\title{
WELCOMING REMARKS To The Oceanography Society At its Inaugural MeEting
}

\begin{abstract}
$\mathrm{W}$ ELCOME TO THE Monterey Bay. I know I am speaking for all of the people in the Monterey Bay area who are interested in ocean science when I tell you how greatly honored and pleased we are to have the Inaugural Meeting of The Oceanography
\end{abstract}

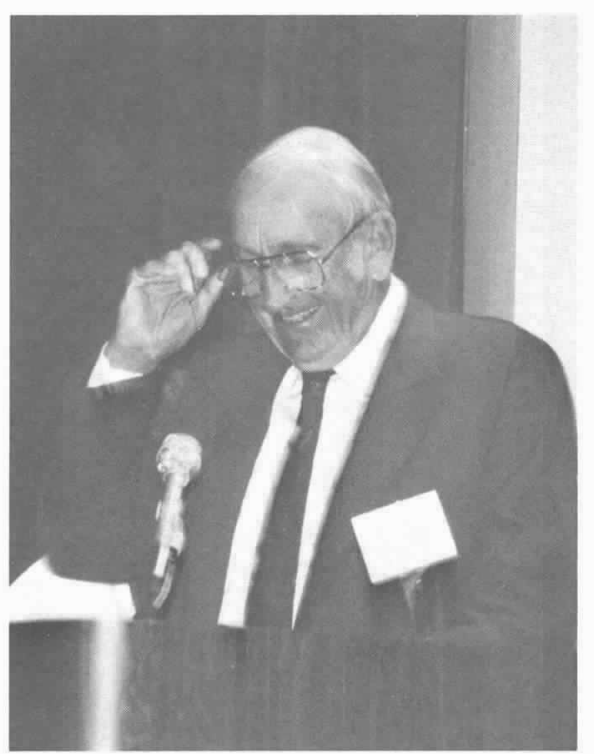

David Packard

Society here this week. This event has a rather special personal significance for me because, over the past ten years or so, I have become addicted to the vision that within the next few years the Monterey Bay will become one of the major world class centers for ocean science. I base this vision on my realization that the oceans are one of the major remaining frontiers of opportunity.

One of my friends recently described a frontier in this way. He said, "It's that place in American mythology where things are wild and unknown, where mysteries and wonders await discovery." The oceans certainly qualify as a remaining frontier in

Editor's Note: The above is a slightly condensed version of Mr. Packard's opening remarks, delivered on August 28, 1989.

\author{
By David Packard \\ Chairman of the Board \\ Hewlett-Packard Company
}

that romantic description. They also qualify as an important frontier in a more pragmatic way. There is much we do not yet know about the oceans, and thus, there is new scientific knowledge to be discovered. The oceans contain major resources of economic value, the potential of which has by no means been fully realized, and thus, there are important economic benefits to be developed. In my humble opinion, the oceans are a more important frontier for research that will bring more tangible benefits to the world than space, or high energy physics, or other areas that have received a high level of public interest and therefore political support. It is about time someone gave ocean science more attention.

I am only a novice and a newcomer to this field, and I realize that speaking to this distinguished audience about the importance of ocean science is simply preaching to the choir. Even so, I want to take a few minutes to tell you about the Monterey Bay Aquarium and the Monterey Bay Aquarium Research Institute, MBARI, because they are the reason for my interest and involvement in ocean science.

A little over ten years ago the members of our family foundation decided that we should develop some worthy programs of our own, instead of just responding to the many requests to provide funds for worthy projects that were being presented to us for consideration. One of the first ideas we considered was the possibility of building an aquarium on the site of the old Hovden Cannery next to the Hopkins Marine Station here on the Monterey Bay. Our first step was to commission a feasibility study, because I wanted to be sure such an aquarium would be of interest and value to the people who lived here or who visited this area. I decided that the only really viable measure of the value of an aquarium here would be whether we could build an aquarium that would be self-supporting over the long term.
The feasibility report was positive, indicating that an aquarium would be of great interest to a large audience of residents and visitors, it could be self-supporting, and it might cost $\$ 10$ million. Armed with this advice, we established the Monterey Bay Aquarium Foundation, selected a group of scientific advisors, hired a firm of architects, and went to work. We did not establish a firm budget, but of course we had the $\$ 10$ million estimate in mind. This soon became a family project including my wife, Lucile, two daughters, Nancy and Julie, and a son-in-law, Robin Burnett. There were several other people who had a major influence in our decision to go ahead: Steve Webster, who is now the director of the educational program at the Aquarium, and Chuck Baxter, who is now on the scientific staff at MBARI. Dave Powell helped in the design of the water system, the display tanks, and all of the details necessary to provide the best possible environment for the specimens we planned to display.

We established some important guidelines at the beginning. We decided the Aquarium should concentrate on the natural history of the Monterey bay; it should be educational as well as enjoyable; and it should have a large participation from the local community.

We knew practically nothing about aquariums, but we visited nearly all of the aquariums in the United States and several in other parts of the world, including the Orient. I soon realized that we had the unique opportunity to design and build one of the best aquariums in the world, but to do that everything must be done in the best way possible. I concluded that we should do as much of the work as possible ourselves. For example, we set up a shop in Sand City to make fiberglass-reinforced tanks, artificial rocks, and anything else we might want in fiberglass plastic. We could have contracted outside for this work, but I thought we might want to do some things 
that had not been done before. The life-size gray whale and her calf, the two life-size killer whale models, and our exhibit of dolphin models would have been difficult to obtain from outside sources. I also bought equipment to make fiberglass-reinforced cement panels. In looking at other aquariums, it was obvious there were serious corrosion problems in using dry-wall and other common construction materials around the exhibit tanks, and fiberglassreinforced cement appeared to be an ideal material. It was corrosion-proof, fireproof, and should last forever. There were not many outside sources for this work.

As we proceeded with the design. we chose what we thought would be the best material for the construction and the best designs for the artificial habitats to house and display the specimens. This, of course. played havoc with the $\$ 10$ million estimate. and the cost ended up at over four times that figure. As you might expect. I have been chided that this was a larger fractional cost over-run than I ever encountered at the Pentagon.

This concentration on quality, I am pleased to report, has really paid off. The Aquarium will have been in operation for five years this October. It looks just as good as the day it was opened, after nine million visitors. It has not only paid its way but has built up a surplus adequate to finance a major expansion, which is in the early stages of design.

In the course of planning and building the Aquarium, we realized that we should have some associated research. The most obvious was that which would help to improve the operation of the Aquarium. Because of our research on sea otters, the Aquarium is the only place that has been successful in raising stranded sea otter pups. Just last week, we sent two from the oil spill area in Alaska to their new home in the Vancouver Aquarium in British Columbia. Although the research we have done at the
Aquarium has contributed to its successful operation, we began to realize three or four years ago that the Monterey Bay area could become a real world-class center for ocean science. We decided this should not be a mission of the Aquarium Foundation, but that a separate foundation should be established to do ocean science research on an extensive and long-term basis.

That was the genesis of the Monterey Bay Aquarium Research Institute. We wanted the Aquarium to be closely associated with MBARI in order to have exhibits at the Aquarium which would be difficult to duplicate anywhere else. As we began the establishment of MBARI, we realized it would be desirable to have good relationships with other organizations in the country that are involved in this field. We thought it was particularly important to work closely with those organizations around the Monterey Bay. We have tried to do both. This meeting is most encouraging, for it is what we hoped would happen sooner or later.

There were three areas of developing technology that I thought would make research in the deep waters of the oceans much more effective in the future. One was the progress that was being made in unmanned remotely-operated vehicles (ROV's). The second was the progress being made in instrumentation tor chemical analysis. The third is the progress that is being made in computer science and data communication. Deep water research involves immense amounts of data. I have the impression that much more time is being spent in collecting data than in looking at it and analyzing it. We believe that situation can be greatly improved.

When we started MBARI, we thought operating funding of $\$ 3$ million a year would be adequate, and both Dr. Barber and Dr. Lee, our two key people, agreed to join us at that budget level. After we got started, we decided that $\$ 3$ million was not enough to do what we wanted to do, and we have increased the budget level to $\$ 5$ million. I realize we will have to lind or provide funding at a higher level as our program expands, but I thought you might like to hear about what we have done thus far. By providing funding without strings, except for a bit ol personal supervision by me, we established the foundation, had a nationwide search for talent, brought an outstanding group of scientists and engineers together. designed and acquired the first ROV and mother ship, and had it operational. all in just over one year. We could not complete our facilities at Moss Landing as quickly because it has taken over a year to get the necessary permit. Those facilities will be completed this fall, about two and a half years from the time we started.

As I am sure you all know, progress in scientific research is highly dependent on the instrumentation and equipment available to the scientists doing the research. To deal with this problem more effectively, we have established a management structure in which the scientists and engineers are working in parallel with each other. in personal contact on a daily basis. This arrangement greatly facilitates communication, eliminates reams of paper work, and as I had hoped, is working extremely well.

I hope you have concluded from my remarks that I am very proud of what MBARI has done in a relatively short time. I hasten to add that I know we do not have all of the answers by any means as how best to explore this frontier of the deep oceans. I am sure that over the next three days we will benefit from the wisdom and experience of you who are here from across the country. I hope the meetings here this week will mark the beginning of a long and fruitful relationship among all of the organizations and people who are challenged by the exciting frontier of the deep oceans of the world. $\square$ 